\title{
The effect of montelukast on lung function and exhaled nitric oxide in infants with early childhood asthma
}

\author{
D.A. Straub*, A. Moeller*, S. Minocchieri*, J. Hamacher", F.H. Sennhauser*, \\ G.L. Hall* and J.H. Wildhaber*
}

ABSTRACT: Effective treatment of respiratory symptoms, airway inflammation and impairment of lung function is the goal of any asthma therapy. Although montelukast has been shown to be a possible add-on therapy for anti-inflammatory treatment in older children, its efficacy in infants and young children is not well known. The aim of this study was to investigate its effect in infants and young children with early childhood asthma.

In a prospective randomised double-blind placebo-controlled study, 24 young children (10-26 months) with wheeze, allergy and a positive family history of asthma consistent with the diagnosis of early childhood asthma were randomised to receive montelukast $4 \mathrm{mg}$ or placebo. The forced expiratory volume in $\mathbf{0 . 5}$ seconds (FEV0.5) was measured using the raised volume rapid thoracic compression technique, and fractional exhaled nitric oxide (FeNO) and symptom scores were determined.

No change was noted in FEV0.5, FeNO or symptom score in the placebo group following the treatment period. In contrast, significant improvements in mean \pm SD FEV0.5 (189.0 \pm 37.8 and $214.4 \pm 44.9 \mathrm{~mL}$ before and after treatment, respectively), FeNO (29.8 \pm 10.0 and $19.0 \pm 8.5 \mathrm{ppb})$ and median symptom score (5.5 and 1.5) were noted following treatment with montelukast.

In conclusion, montelukast has a positive effect on lung function, airway inflammation and symptom scores in very young children with early childhood asthma.

KEYWORDS: Asthma, infant, inflammation, lung function test, montelukast, nitric oxide

D espite the improvement in diagnostic procedures and the availability of efficient anti-inflammatory drugs, the treatment of young children suffering from recurrent episodes of wheeze is still unsatisfactory. This may be explained by the heterogeneity of causes of recurrent wheeze in this age group. Although many children suffer from recurrent episodes of wheeze in early childhood, the majority of early recurrent wheezers suffer from transient illness (transient wheezers), and only a small number of infants with recurrent wheeze in early childhood (persistent wheezers) develop asthma in later life [1].

It may well be that only young children with persistent wheeze respond to and benefit from anti-inflammatory asthma therapy. Therefore, it would be important to distinguish infants with persistent wheeze from those with transient wheeze.

Another potential explanation for the lack of response of wheezing episodes to inhaled treatment in this young age group is the difficulty of drug administration. The low level of cooperation in this age group may lead to decreased compliance, and, in those children in whom compliance is good, there may be decreased lung deposition, causing a marginal effect of this kind of treatment [2]. It has been found that, with very high doses of inhaled or systemic anti-inflammatory treatments, a response can be achieved in recurrent wheezers [3]. Montelukast (Singulair ${ }^{\circledR}$ ) is considered to be a potential alternative or addon for anti-inflammatory treatment in older children with asthma. Owing to its easy and uncomplicated oral administration, montelukast may be advantageous over inhaled steroids in the treatment of young children.

Early diagnosis of children suffering from early childhood asthma is desirable in order to minimise asthma exacerbations and prevent potential chronic lung function abnormalities. Today, early diagnosis is often based on clinical history, physical examination and nonspecific laboratory tests. Based on the work of MARTINEz et al. [1],

\section{AFFILIATIONS}

*Division of Respiratory Medicine, University Children's Hospital Zurich, Zurich, Switzerland.

\#University of Homburg, Homburg/ Saar, Germany.

CORRESPONDENCE

D.A. Straub

Division of Respiratory Medicine

University Children's Hospital

Steinwiesstrasse 75

CH-8032 Zürich

Switzerland

Fax: 4112667171

E-mail: daniel.straub@kispi.unizh.ch

Received:

March 152004

Accepted after revision:

September 282004 
family history of asthma and detection of allergies may be helpful in diagnosis. Since the mid-1990s, new diagnostic procedures have been developed. In particular, fractional exhaled nitric oxide ( $\mathrm{FeNO}$ ) has been demonstrated to be a reliable marker of airway inflammation and to serve as an additional noninvasive diagnostic tool for airway inflammation in association with asthma [4,5]. FeNO is elevated in asthmatic compared with healthy children [4-6] and reduced during anti-inflammatory therapy [7-11]. FeNO can be measured even in early childhood [12].

Montelukast, a leukotriene (LT) receptor antagonist, acts on $\mathrm{LTC}_{4}, \mathrm{LTD}_{4}$ and $\mathrm{LTE}_{4}$, and, therefore, on airway inflammation and bronchoconstriction. $\mathrm{LTC}_{4}, \mathrm{LTD}_{4}$ and $\mathrm{LTE}_{4}$ play an integral role in the pathophysiology of asthma. In addition to functioning as potent bronchoconstrictors, these mediators contribute to the airway inflammation by increasing airway blood flow and vascular permeability, allowing the exudation of plasma macromolecules and contributing to the airway oedema that characterises asthma and induces mucus secretion [13-15]. The LT receptor antagonist montelukast is known to have a protective effect against bronchoconstriction [16]. In clinical studies, this effect has been confirmed in terms of exercise- and allergen-induced bronchoconstriction in adults, as well as in children [17-20]. Furthermore, many studies demonstrate the effectiveness of montelukast, but there are no studies addressing the improvement of lung function in treated infants and young children.

Montelukast is effective and safe [18, 21, 22], and registered for use in adults and children aged $>6$ months. Although some studies have demonstrated a positive effect on markers of airway inflammation $[9,18,20,23,24]$, namely FeNO and levels of sputum eosinophils and eosinophil cationic protein, others have not [25]. Montelukast is orally administered once daily and is therefore easy to apply. In contrast to inhalation therapy, oral application has the advantage of quantifiable drug deposition, especially in young children. Therefore, it is supposable that montelukast could be an effective therapy in early childhood asthma.

The aim of the present study was to investigate the therapeutic effect of montelukast in a well-defined group of very young children with recurrent wheeze and a positive family history of asthma and allergy, and, therefore, most likely to represent the group of persistent wheezers.

\section{METHODS \\ Subjects}

The Division of Respiratory Medicine (University Children's Hospital Zurich, Zurich, Switzerland) is attended by $600-700$ children aged $<5$ yrs with a history of wheezing each year. Of these, all infants with a history of recurrent wheeze, proven allergy (positive skin-prick test or radioallergosorbent test (class $>1$ ) result) to food and/or inhaled allergens, elevated FeNO $(>15 \mathrm{ppb})$ and a positive family history of asthma were asked to participate in the study. Over 12 months, 24 children (13 male), mean age 17 months (range 10-26 months), were recruited. A total of 13 infants were on inhaled bronchodilators (salbutamol or terbutaline sulphate) prior to the study; this therapy was stopped $\geqslant 24 \mathrm{~h}$ prior to the first test. None of the children was on any anti-inflammatory treatment.

\section{Study design}

The young children were randomised to two groups: a treatment group receiving montelukast (Singulair ${ }^{\circledR}$; Merck \& Co. Inc., Whitehouse Station, NJ, USA) $4 \mathrm{mg}$ daily, and a placebo group receiving one placebo tablet daily. Before (visit 1) and after 4 weeks of treatment (visit 2), lung function tests and FeNO measurements were performed. The Specialised Subcommittee of the Committee of Ethics of the University Children's Hospital Zurich approved the study and written informed consent was obtained from the parents.

\section{Lung function measurements}

Forced expiratory volumes were measured by the raised volume rapid thoracic compression technique using the Mobile Infant Respiratory Lung Function Laboratory (EcoMedics, Dürnten, Switzerland). This technique has been described previously by TURNER et al. [26]. All children were examined asleep in the supine position following an oral or rectal dose of chloral hydrate $\left(70-100 \mathrm{mg} \cdot \mathrm{kg}\right.$ body weight $\left.{ }^{-1}\right)$. During three consecutive cycles, lung volume was manually raised to an inflation pressure of $2 \mathrm{kPa}$. After the first and second inflation, the infants expired passively. Following the third inflation, forced expiration was initiated by compressing the chest and abdomen with a rapidly inflatable jacket at endinspiration. Flow was measured using an ultrasonic flow meter (Spiroson ${ }^{\circledR}$; EcoMedics), and mouth pressure was measured at a side-port of the face-mask connector. All signals were collected and analysed by computer with data acquisition and analysis software (SpiroWare ${ }^{\circledR}$; EcoMedics) in order to calculate the forced expiratory volume by digital integration of flow. The forced expiratory volume in 0.5 seconds (FEV0.5) was reported as the mean of three measurements of good quality.

\section{Exhaled nitric oxide measurements}

FeNO was measured using the single-breath positive expiratory pressure technique [12]. This technique has previously been shown to allow repeated measurements with a good coefficient of repeatability (5.1 ppb for two measurements $1 \mathrm{~h}$ apart and $7.3 \mathrm{ppb}$ for two measurements 4 weeks apart) [11]. FeNO was determined using a chemiluminescence analyser (CLD 77 AM; EcoMedics) with a sampling rate of $100 \mathrm{~Hz}$ and a sampling flow of $200 \mathrm{~mL} \cdot \mathrm{min}^{-1}$. Exhaled $\mathrm{NO}$ was measured after application of three inflatory manoeuvres to a maximum of $2 \mathrm{kPa}$. At the third inflation, after two manoeuvres with normal exhalation, the child performed a forced exhalation against an expiratory resistance $(0.5-2.0 \mathrm{kPa})$ using manually controlled jacket pressure to achieve a constant expiratory flow of $15 \mathrm{~mL} \cdot \mathrm{s}^{-1}$. The FeNO measurements were performed repetitively to achieve a minimum of three technically acceptable measurements within a $10 \%$ range.

\section{Symptom scores}

Symptom scores were calculated using a scoring system as previously described by NOBLE et al. [27]. Respiratory symptoms (cough, wheeze and shortness of breath) were recorded for each day and night of the 4-week treatment period. Symptoms were scored from 0 (no symptoms) to 3 (severe symptoms). The median symptom scores from the first and last week were analysed for each parameter and also summed to give a $24-\mathrm{h}$ total symptom score. The maximum achievable total symptom score was 18 and the minimum 0 . 


\section{Statistical analysis}

The analysis consisted of a repeated-measurement design for the variables FEV0.5 and FeNO. Results were expressed as mean $\pm \mathrm{SD}$ or, if not normally distributed or in the case of categorical variables, as median (range). Two-tailed tests were performed in the case of normal distribution unpaired t-tests or, where adequate, repeated-measurement ANOVA was used to detect differences in values between the two groups; otherwise, the Mann-Whitney U-test was used. A p-value of $\leqslant 0.05$ was considered significant.

\section{RESULTS}

The overall mean \pm SD age, weight and length of the 24 infants (13 male, 11 female) were $18.3 \pm 4.2$ months, $11.1 \pm 0.7 \mathrm{~kg}$ and $79.2 \pm 9.4 \mathrm{~cm}$. There were no differences in age, weight and length between the two groups ( $\mathrm{p}=0.1,0.7$ and 0.9 , respectively). The lung function parameter FEV0.5, FeNO and symptom scores for the first and last visit for both the montelukast and placebo groups are shown in table 1 . In the montelukast group, nine out of 12 patients were sensitised only to food allergens, two only to aeroallergens and one showed combined food and aeroallergen sensitisation. All except one child (eight out of nine) with sensitisation to food allergens and one with sensitisation to aeroallergens (one out of two) suffered from atopic dermatitis. In the placebo group, seven patients were sensitised only to food allergens, two only to aeroallergens and three to food and aeroallergens. All patients (10 out of 10 ) with sensitisation to food allergens, but none with sensitisation to aeroallergens, suffered from atopic dermatitis.

\section{Lung function measurements}

Mean FEV0.5 significantly improved in the treated group, from $189.0 \pm 37.8 \mathrm{~mL}$ (mean $\pm \mathrm{SD}$ ) before to $214.4 \pm 44.9 \mathrm{~mL}$ after treatment with montelukast for 4 weeks $(p=0.038)$. In contrast, mean FEV0.5 did not differ significantly in the placebo group, going from $161.0 \pm 44.0 \mathrm{~mL}$ before to $166.6 \pm 36.0 \mathrm{~mL}$ after 4 weeks of treatment ( $p=0.26$; fig. 1$)$.

\section{Exhaled nitric oxide measurements}

Baseline FeNO tended to be slightly lower in the placebo group; however, the difference was nonsignificant $(p=0.37)$. FeNO decreased significantly in the montelukast group $(29.8 \pm 10.0$ to $19.0 \pm 8.5 \mathrm{ppb} ; \mathrm{p}=0.01)$, but not in the placebo group $(33.4 \pm 9.4$ to $34.5 \pm 8.3 \mathrm{ppb} ; \mathrm{p}=0.25$; fig. 2 ). The difference between the change in FeNO in the treatment group and that in the placebo group was significant $(p=0.04)$. No correlation was found between FeNO or decrease in FeNO after montelukast and type

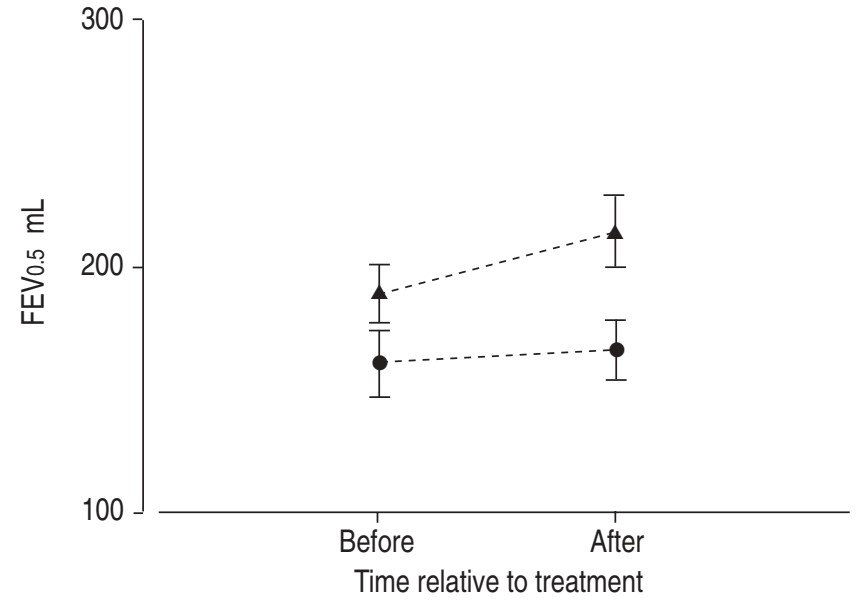

FIGURE 1. Lung function before and after 4 weeks of treatment with montelukast $(\mathbf{\Delta})$ or placebo $(\mathbf{O})$. Data are presented as mean $\pm \mathrm{SD}$. There was significant improvement after therapy with montelukast $(p=0.038)$. FEV0.5: forced expiratory volume in 0.5 seconds.

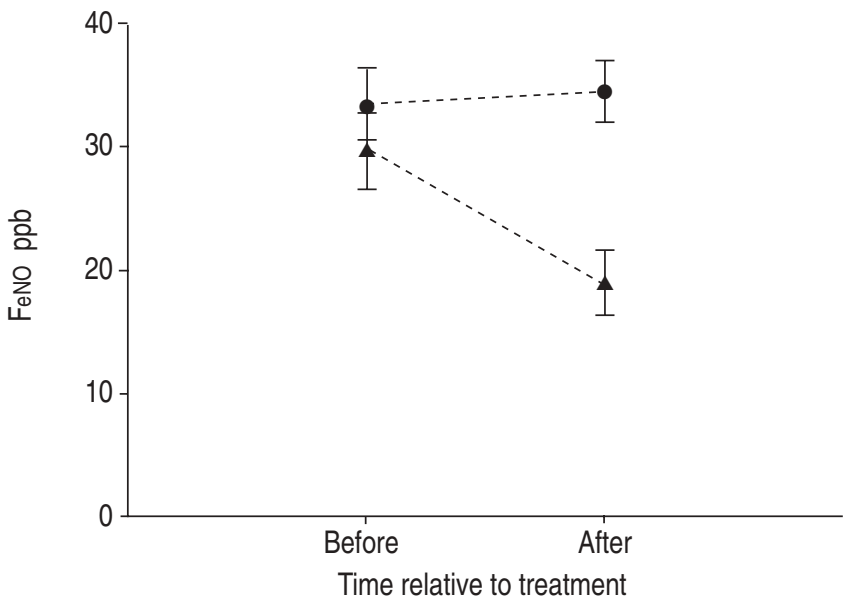

FIGURE 2. Fractional exhaled nitric oxide (FeNO) before and after 4 weeks of treatment with montelukast $(\boldsymbol{\Lambda})$ or placebo $(\mathbf{O})$. Data are presented as mean $\pm \mathrm{SD}$. There was a significant decrease in the treatment group $(p=0.04)$.

of allergy (food or aeroallergens) ( $\mathrm{p}=0.31$ and 0.64 for active and placebo group, respectively) or presentation of atopic dermatitis $(\mathrm{p}=0.33$ and 0.21$)$.

\begin{tabular}{|c|c|c|c|c|c|c|}
\hline & \multicolumn{3}{|c|}{ Placebo } & \multicolumn{3}{|c|}{ Montelukast } \\
\hline & Visit 1 & Visit 2 & $p$-value & Visit 1 & Visit 2 & $p$-value \\
\hline FeNO ppb & $33.4 \pm 9.4$ & $34.5 \pm 8.3$ & 0.25 & $29.8 \pm 10.0$ & $19.0 \pm 8.5$ & 0.01 \\
\hline
\end{tabular}

Data are presented as mean \pm SD or median (95\% confidence interval), unless otherwise stated. 


\section{Symptoms}

The overall median symptom score before treatment was 4.5 (95\% confidence interval 3.4-5.7), reflecting the clinical signs of mild disease activity. In the treatment group, the median (range) total symptom score improved significantly from 5.5 $(0-9)$ to $1.5(0-6 ; p=0.04)$, whereas, in the placebo group, the symptom score changed from $3.0(1-8)$ to 4.0 (1-8) after 4 weeks $(p=0.35)$.

\section{DISCUSSION}

In infants and young children exhibiting symptoms compatible with early childhood asthma, defined as recurrent wheeze, proven allergy and a positive history of parental asthma, the present results demonstrate a positive effect of treatment with montelukast. Montelukast caused a decline in airway inflammation, reflected by a significant fall in FeNO, and an improvement in lung function, confirmed by a significant improvement in FEV0.5. A number of studies have investigated the effectiveness of anti-inflammatory treatment in asthmatic infants. However, although most researchers investigated clinical signs, respiratory symptoms and the need for reliever medication, only a few studies included objective parameters, such as lung function data or markers of inflammation. A recent review article reported on 28 studies investigating the clinical effect of inhaled steroids in childhood asthma [28], only one of which additionally performed lung function tests in preschoolers and demonstrated a significant improvement in lung function after 8 weeks' therapy with inhaled steroids [29].

Cysteinyl LTs (cys-LTs) are known to cause airway inflammation (infiltration of eosinophil granulocytes and mucosal oedema), bronchial obstruction and increased bronchial responsiveness [13-15]. As a cys-LT1 receptor antagonist, montelukast is known to have an anti-inflammatory effect, which has been demonstrated in several studies. Montelukast has been found to cause a significant decrease in the levels of sputum eosinophil cationic protein [23], soluble interleukin-2 receptor, interleukin-4 and soluble intercellular adhesion molecule-1 and eosinophil blood counts [18]. While studies in adults $[20,25,30]$ and school-aged children $[9,31]$ treated with montelukast have shown a fall in FeNO, the data from the present study illustrate that this effect of montelukast on FeNO is also present in infants and very young children aged $<2$ yrs suffering from early childhood asthma. A significant reduction in FeNO after 4 weeks of treatment with montelukast has been shown in the present study. To date, there are no further published data on objective measurements of airway inflammation in infants treated with montelukast. The results of the present study should be treated with some caution because of the small patient numbers after subdividision into the treatment and placebo groups. However, similar improvements in FeNO have previously been reported in infants treated for 4 weeks with budesonide or inhaled fluticasone dipropionate $[11,32]$.

Cys-LTs, mainly $\mathrm{LTC}_{4}$ and $\mathrm{LTD}_{4}$, are known to be potent bronchoconstrictive substances, and the LT receptor antagonist montelukast is known to exhibit a protective effect against bronchoconstriction [16]. In clinical studies, this beneficial effect has been confirmed in terms of exercise- and allergeninduced bronchoconstriction in adults, as well as children [1720]. Many studies have demonstrated the clinical effectiveness of montelukast in adults and children, but, to date, there are no further studies reporting an improvement in lung function in infants and young children. In the present study, the FEV0.5, assessed by the raised volume rapid thoracic compression technique, showed significant improvement after treatment with montelukast. Using the same technique in infants with a history of recurrent wheeze but asymptomatic at the time of investigation, HAYDEN et al. [33] could not detect a significant improvement in lung function after administration of a bronchodilator. In contrast to the study of HAYDEN et al. [33], the infants in the present study were symptomatic at the time of the first visit, and, therefore, some potential for improvement in lung function may have been expected. In the present study, the infants treated with montelukast showed a $12 \%$ improvement in FEV0.5 compared with $3.5 \%$ in the placebo group. The clinical relevance of this change in FEV0.5 is difficult to interpret. The percentage change in lung function in the present study is comparable to findings in older children. The Paediatric Montelukast Study Group found an improvement in forced expiratory volume in one second of $8.2 \%$ in the treatment group compared with $3.6 \%$ in the placebo group [21]. Using a comparable technique in healthy infants, GOLDSTEIN et al. [34] found a mean improvement of $2.2 \%$ after administration of salbutamol, whereas, after 4 weeks' treatment with inhaled steroids, MoELLER et al. [32] found a $17 \%$ improvement in FEV0.5.

Parentally reported symptom scores are used in most studies in infants. Although they do not always appear to be reliable $[35,36]$, they were used as an additional tool in the present study. Symptom scores were not a major outcome in the current study due to the short intervention period and their variable nature. Baseline symptom scores were higher in the montelukast group; however, this difference was nonsignificant. There was a significant decline in parentally reported symptom scores in the montelukast group, suggesting clinical improvement in treated patients. Although both lung function and symptoms improved, there was no correlation between symptom scores and lung function. However, the treatment period was relatively short, and more significant changes in lung function may occur with longer anti-inflammatory treatment. The present findings are in accordance with the study of WILDHABER et al. [36], which showed that objective measurements of FEVt correlate well with the overall health assessment of the study physician, but not the assessment of the caregiver.

In summary, whereas most studies in very young children with recurrent wheeze have shown little or no effect of antiinflammatory asthma treatment [37], the present study has shown that anti-inflammatory treatment with montelukast may be beneficial in a well-defined subgroup of wheezy infants: those with recurrent wheeze, a family history of asthma, raised fractional exhaled nitric oxide and a positive allergy test result. The results of the present study may be explained by the fact that wheeze in infancy consists of an extremely heterogeneous group, and most previous studies have not investigated the therapeutic effect in a subgroup but only in wheezing infants in general. The present inclusion criteria ensure a degree of homogeneity with regard to phenotype and maximise the likelihood of persistent airway inflammation due to atopic early childhood asthma being 
present. These findings are in accordance with a previous study looking at the effect of inhaled steroids in a similar subgroup [32]. The present study is based on a short-term intervention with montelukast and, therefore, not expected to predict the long-term benefit of this therapy. This question, as well as the value of montelukast as an add-on therapy in this age group, should be investigated in further studies. The present results stress the importance of an exact clinical diagnosis of recurrent wheeze in infancy for successful treatment. As in clinical practice, inhaled treatment may be difficult in this age group and montelukast may serve as an alternative first treatment in young children with early childhood asthma.

\section{REFERENCES}

1 Martinez FD, Wright AL, Taussig LM, Holberg CJ, Halonen M, Morgan WJ. Asthma and wheezing in the first six years of life. $N$ Engl J Med 1995; 332: 133-138.

2 Salmon B, Wilson NM, Silverman M. How much aerosol reaches the lungs of wheezy infants and toddlers? Arch Dis Child 1990; 65: 401-403.

3 Volovitz B, Soferman R, Blau H, Nussinovitch M, Varsano I. Rapid induction of clinical response with a short-term high-dose starting schedule of budesonide nebulizing suspension in young children with recurrent wheezing episodes. J Allergy Clin Immunol 1998; 101: 464-469.

4 Kharitonov SA, Yates D, Springall DR, et al. Exhaled nitric oxide is increased in asthma. Chest 1995; 107: Suppl. 3, 156S-157S.

5 Jatakanon A, Lim S, Kharitonov SA, Chung KF, Barnes PJ. Correlation between exhaled nitric oxide, sputum eosinophils, and methacholine responsiveness in patients with mild asthma. Thorax 1998; 53: 91-95.

6 Byrnes CA, Dinarevic S, Shinebourne EA, Barnes PJ, Bush A. Exhaled nitric oxide measurements in normal and asthmatic children. Pediatr Pulmonol 1997; 24: 312-318.

7 Baraldi E, Azzolin NM, Zanconato S, Dario C, Zacchello F. Corticosteroids decrease exhaled nitric oxide in children with acute asthma. I Pediatr 1997; 131: 381-385.

8 Baraldi E, Dario C, Ongaro R, et al. Exhaled nitric oxide concentrations during treatment of wheezing exacerbation in infants and young children. Am J Respir Crit Care Med 1999; 159: 1284-1288.

9 Bisgaard H, Loland L, Oj JA. NO in exhaled air of asthmatic children is reduced by the leukotriene receptor antagonist montelukast. Am J Respir Crit Care Med 1999; 160: 1227-1231.

10 Carra S, Gagliardi L, Zanconato S, et al. Budesonide but not nedocromil sodium reduces exhaled nitric oxide levels in asthmatic children. Respir Med 2001; 95: 734-739.

11 Wildhaber JH, Moeller A, Hall GH, Sennhauser FH, Stick SM. Levels of exhaled nitric oxide in recurrently wheezy infants are decreased following inhaled steroid therapy. Schweiz Med Wochenschr 2000; 130: 529-534.

12 Wildhaber JH, Hall GL, Stick SM. Measurements of exhaled nitric oxide with the single-breath technique and positive expiratory pressure in infants. Am J Respir Crit Care Med 1999; 159: 74-78.
13 Salvi SS, Krishna MT, Sampson AP, Holgate ST. The antiinflammatory effects of leukotriene-modifying drugs and their use in asthma. Chest 2001; 119: 1533-1546.

14 Bisgaard H. Pathophysiology of the cysteinyl leukotrienes and effects of leukotriene receptor antagonists in asthma. Allergy 2001; 56: 7-11.

15 Marom Z, Shelhamer JH, Bach MK, Morton DR, Kaliner M. Slow-reacting substances, leukotrienes $\mathrm{C}_{4}$ and $\mathrm{D}_{4}$, increase the release of mucus from human airways in vitro. Am Rev Respir Dis 1982; 126: 449-451.

16 Bronsky EA, Kemp JP, Zhang J, Guerreiro D, Reiss TF. Dose-related protection of exercise bronchoconstriction by montelukast, a cysteinyl leukotriene-receptor antagonist, at the end of a once-daily dosing interval. Clin Pharmacol Ther 1997; 62: 556-561.

17 Phipatanakul W, Nowak-Wegrzyn A, Eggleston PA, et al. The efficacy of montelukast in the treatment of cat allergen-induced asthma in children. J Allergy Clin Immunol 2002; 109: 794-799.

18 Stelmach I, Jerzynska J, Kuna P. A randomized, doubleblind trial of the effect of treatment with montelukast on bronchial hyperresponsiveness and serum eosinophilic cationic protein $(\mathrm{ECP})$, soluble interleukin 2 receptor (sIL2R), IL-4, and soluble intercellular adhesion molecule 1 (sICAM-1) in children with asthma. J Allergy Clin Immunol 2002; 109: 257-263.

19 Kemp JP, Dockhorn RJ, Shapiro GG, et al. Montelukast once daily inhibits exercise-induced bronchoconstriction in 6- to 14-year-old children with asthma. J Pediatr 1998; 133: 424-428.

20 Leigh R, Vethanayagam D, Yoshida M, et al. Effects of montelukast and budesonide on airway responses and airway inflammation in asthma. Am J Respir Crit Care Med 2002; 166: 1212-1217.

21 Knorr B, Matz J, Bernstein JA, et al. Montelukast for chronic asthma in 6- to 14-year-old children: a randomized, double-blind trial. JAMA 1998; 279: 1181-1186.

22 Knorr B, Franchi LM, Bisgaard H, et al. Montelukast, a leukotriene receptor antagonist, for the treatment of persistent asthma in children aged 2 to 5 years. Paediatrics 2001; 108: E48.

23 Strauch E, Moske O, Thoma S, et al. A randomized controlled trial on the effect of montelukast on sputum eosinophil cationic protein in children with corticosteroiddependent asthma. Pediatr Res 2003; 54: 198-203.

24 Ghiro L, Zanconato S, Rampon O, Piovan V, Pasquale MF, Baraldi E. Effect of montelukast added to inhaled corticosteroids on fractional exhaled nitric oxide in asthmatic children. Eur Respir J 2002; 20: 630-634.

25 Kanniess F, Richter K, Bohme S, Jorres RA, Magnussen H. Montelukast versus fluticasone: effects on lung function, airway responsiveness and inflammation in moderate asthma. Eur Respir J 2002; 20: 853-858.

26 Turner DJ, Stick SM, Lesouef KL, Sly PD, Lesouef PN. A new technique to generate and assess forced expiration from raised lung volume in infants. Am J Respir Crit Care Med 1995; 151: 1441-1450.

27 Noble V, Ruggins NR, Everard ML, Milner AD. Inhaled budesonide for chronic wheezing under 18 months of age. Arch Dis Child 1992; 67: 285-288. 
28 Kaditis AG, Gourgoulianis K, Winnie G. Antiinflammatory treatment for recurrent wheezing in the first five years of life. Pediatr Pulmonol 2003; 35: 241-252.

29 Nielsen KG, Bisgaard H. The effect of inhaled budesonide on symptoms, lung function, and cold air and methacholine responsiveness in 2- to 5-year-old asthmatic children. Am J Respir Crit Care Med 2000; 162: 1500-1506.

30 Minoguchi K, Kohno Y, Minoguchi H, et al. Reduction of eosinophilic inflammation in the airways of patients with asthma using montelukast. Chest 2002; 121: 732-738.

31 Bratton DL, Lanz MJ, Miyazawa N, White CW, Silkoff PE. Exhaled nitric oxide before and after montelukast sodium therapy in school-age children with chronic asthma: a preliminary study. Pediatr Pulmonol 1999; 28: 402-407.

32 Moeller A, Franklin P, Hall GL, et al. Inhaled fluticasone dipropionate decreases levels of nitric oxide in recurrently wheezy infants. Pediatr Pulmonol 2004; 38: 250-255.
33 Hayden MJ, Wildhaber JH, LeSouef PN. Bronchodilator responsiveness testing using raised volume forced expiration in recurrently wheezing infants. Pediatr Pulmonol 1998; 26: 35-41.

34 Goldstein AB, Castile RG, Davis SD, et al. Bronchodilator responsiveness in normal infants and young children. Am J Respir Crit Care Med 2001; 164: 447-454.

35 Cane R, Ranganathan S, McKenzie S. What do parents of wheezy children understand by "wheeze"? Arch Dis Child 2000; 82: 327-332.

36 Wildhaber JH, Dore ND, Devadason SG, et al. Comparison of subjective and objective measures in recurrently wheezy infants. Respiration 2002; 69: 397-405.

37 Oommen A, Lambert PC, Grigg J. Efficacy of a short course of parent-initiated oral prednisolone for viral wheeze in children aged 1-5 years: randomised controlled trial. Lancet 2003; 362: 1433-1438. 